\section{Methotrexate Use in a Breastfeeding Patient with Rheumatoid Arthritis}

To the Editor:

Methotrexate (MTX), a folic acid antagonist, is considered the first-line treatment in the management of rheumatoid arthritis (RA) ${ }^{1}$. As a result of embryotoxic and teratogenic effects, MTX is discontinued in women planning to conceive ${ }^{2,3,4}$. RA disease activity often decreases during pregnancy and increases after delivery ${ }^{5}$. Thus, women with RA are monitored closely following delivery. Breastfeeding may also pose challenges, attributable to the concern about drug exposure for the infant and potential drug-related adverse effects. The American Academy of Pediatrics and other reviews recommend the avoidance of MTX in breastfeeding women ${ }^{3,4,6}$.

There is limited evidence of mammary excretion of MTX. One case report from 1972 describes MTX milk levels in a 25-year-old lactating mother with choriocarcinoma being treated with oral MTX at a dose of $22.5 \mathrm{mg}$ per day ${ }^{7}$. Milk, blood, and urine samples were obtained at 2-h intervals on the first day of treatment and MTX levels were assessed using a bioassay with partially purified dihydrofolate reductase from mouse leukemia cells. MTX was detected in breast milk and serum following oral administration of MTX with peak breast milk level being $5.0 \mathrm{nM}$ at $9 \mathrm{~h}$, while peak serum levels being a maximum of $1.8 \mathrm{nM}$ at $6 \mathrm{~h}$. The cumulative excretion of MTX in the first $12 \mathrm{~h}$ after oral administration was 10,000 -fold more in the urine than in breast milk $(0.32 \mu \mathrm{g}$ in milk, $4.3 \mathrm{mg}$ in urine). Also, based on lipid solubility measurements, $98 \%$ of MTX was found to be in lipid insoluble form at physiologic $\mathrm{pH}$, demonstrated by the limited excretion of the drug in breast milk. Given the low rate of secretion and lipid-insoluble nature, MTX can be considered during lactation.

In our report, we describe a case of a 34-year-old multiparous nonsmoker who continued to breastfeed her infant while being treated with MTX postpartum for her active RA.

The patient was initially diagnosed with RA at the age of 23 years, 7 months after her first pregnancy. She was treated with sulfasalazine (SSZ) and oral MTX, and continued this regimen for about 7 years. Medications were discontinued by the patient because she was lost to followup. When she was first reviewed by one of the authors (CT), she was noted to have active RA [Clinical Disease Activity Index (CDAI) 54] and was treated with hydroxychloroquine (HCQ) $400 \mathrm{mg}$ daily and subcutaneous (SC) MTX $25 \mathrm{mg}$ weekly. Her disease activity score decreased (CDAI 10), allowing for the discontinuation of MTX (while continuing HCQ) and the eventual safe delivery of her third child. Postpartum, she had a significant flare, resulting in the addition of SSZ to her HCQ regimen. As a result of persistent joint activity despite treatment, she reluctantly weaned her infant after 8 months of nursing and was again receiving MTX $25 \mathrm{mg}$ (SC) weekly.

She expressed interest in conceiving a fourth child and MTX was discontinued while she was in low disease activity (CDAI 10). She conceived her fourth child later that year. She had several flares during the pregnancy, despite concurrent use of HCQ and SSZ requiring intraarticular steroids and eventually oral prednisone at $10 \mathrm{mg}$ daily at 15 weeks gestational age. She carried to term and delivered her fourth child in May 2012 and nursed her child.

Within 3 months postpartum, she developed a flare of her RA, despite optimal doses of SSZ, HCQ, and prednisone $10 \mathrm{mg}$ daily. A discussion ensued about restarting SC MTX. The patient was reluctant, given her wish to nurse her newborn for a full 12 months, but understood the need to control her disease. Eventually, a decision was made to monitor MTX levels in the breast milk.

The patient received $25 \mathrm{mg} \mathrm{SC} \mathrm{MTX} \mathrm{at} \mathrm{postpartum} \mathrm{day} \mathrm{151.} \mathrm{Maternal}$ serum and breast milk were collected for the first $24 \mathrm{~h}$ after initial MTX injection. Using liquid chromatography-mass spectrometry, MTX concen- trations were quantified. Maternal serum MTX level was $0.92 \mu \mathrm{M} 1 \mathrm{~h}$ after SC dose, and 3 breast milk samples taken at $2 \mathrm{~h}, 12 \mathrm{~h}$, and $24 \mathrm{~h}$ after the initial dose demonstrated $0.05 \mu \mathrm{M}$ levels of MTX, detectable but below the quantitation limits. Assuming that milk concentration of $0.05 \mu \mathrm{M}$ is sustained over the $24 \mathrm{~h}$ post-dose, and that average milk intake of the infant is $150 \mathrm{ml} / \mathrm{kg} / \mathrm{day}$, the infant's oral dose of MTX through breast milk over the first 24 -h post-dose was estimated to be $3.4 \mu \mathrm{g} / \mathrm{kg} /$ day $(22.7 \mu \mathrm{g} / 1 \times 150$ $\mathrm{ml} / \mathrm{kg} /$ day), which was about $1 \%$ of the maternal weight-adjusted dose.

The patient/mother was reassured with these results and decided to continue breastfeeding her 5-month-old infant with weekly dosing of MTX for a further 9 months.

Our unique case highlights the use of parenteral MTX in a breastfeeding patient with RA. Given that breast milk levels of MTX were very low, it was expected that exposure by an infant after $24 \mathrm{~h}$ of weekly MTX dose would be negligible. No adverse clinical effects were noted in the infant. Our case lends support to the use of parenteral weekly MTX in nursing women with active RA. This practice warrants further observation and study.

Supported by the Canadian Institute of Health Research.

J. CARTER THORNE, MD, Rheumatologist, Chief Division of Rheumatology, Medical Director, The Arthritis Program, Southlake Regional Health Centre, Newmarket; THANU NADARAJAH, MD, Rheumatology Fellow, University of Toronto, Adult Rheumatology program; MYLA MORETTI, MSc, Assistant Director, Motherisk Program/Division of Clinical Pharmacology and Toxicology, Hospital for Sick Children; SHINYA ITO, MD, Division Head, Clinical Pharmacology and Toxicology, Department of Pediatrics, Hospital for Sick Children, Toronto, Ontario, Canada.

Address correspondence to Dr. T. Nadarajah, University of Toronto, Medicine, 500 University Ave., Suite 602, Toronto, Ontario M5G 1V7, Canada.E-mail: thanu.nadarajah@gmail.com

\section{REFERENCES}

1. Bykerk VP, Akhavan P, Hazelwood GS, Schieir O, Dooley A, Haraoui B, et al. Canadian Rheumatology Association recommendations for pharmacological management of rheumatoid arthritis with traditional and biologic disease-modifying antirheumatic drugs. J Rheumatol 2011;38:1559-82.

2. Temprano KK, Bandlamudi R, Moore TL. Antirheumatic drugs in pregnancy and lactation. Semin Arthritis Rheum 2005;35:112-21.

3. Martinez Lopez JA, Loza E, Carmona L. Systematic review on the safety of methotrexate in rheumatoid arthritis regarding the reproductive system (fertility, pregnancy, and breastfeeding). Clin Exp Rheumatol 2009;27:678-84.

4. Makol A, Wright K, Amin S. Rheumatoid arthritis and pregnancy: safety consideration in pharmacological management. Drugs 2011;71:1973-87.

5. de Man YA, Dolhain RJ, van de Geijn FE, Willemsen SP, Hazes JM. Disease activity of rheumatoid arthritis during pregnancy: results from a nationwide prospective study. Arthritis Rheum 2008;59:1241-8.

6. American Academy of Pediatrics Committee on Drugs: The transfer of drugs and other chemicals into human milk. Pediatrics 2001;108:776-89.

7. Johns DG, Rutherford LD, Leighton PC, Vogel CL. Secretion of methotrexate into human milk. Am J Obstet Gynecol 1972;112:978-80.

J Rheumatol 2014;41:11; doi:10.3899/jrheum.140263 